\title{
EDITORIAL
}

\section{Microbiologie des eaux usées}

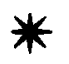

$\boldsymbol{U}^{x+2}$ NE DISSERTATION sur la microbiologie des eaux usées peut être fort différente suivant le présentateur. Un hygiéniste parlera de bactéries pathogènes, bactéries suspectes, virus, parasites, maladies transmissibles et épidémiques, alors qu'un ingénieur en traitement-épuration s'exprimera en termes d'autoépuration, de biodégradation, de bactéries saprophytes, de bactéries telluriques. Dans les deux cas il s'agit bien de microbiologie mais les micro-organismes impliqués sont d'origines et de devenir très différents.

Sans vouloir minimiser à l'excès, plus personne, actuellement et sous nos climats, n'est effrayé par le spectre des grandes pandémies microbiennes et hydriques qui ont ravagé les siècles passés. Pourtant certaines bouffées épidémiques européennes à Vibrio cholerae et biotypes sont là pour nous rappeler que les «mauvaises bactéries» existent toujours. A côté de ces «mauvaises bactéries", et anthropocentriquement parlant, il y en a de "bonnes ", "bonnes bactéries» qui dégradent, plus ou moins aidées par l'homme, non seulement les molécules ancestralement associées mais aussi la masse considérable des molécules synthétisées. Et génie humain contre génie naturel la bataille de l'épuration se déroule, alors que les génies de la synthèse moléculaire se dédoublent pour être aussi génies de la dégradation.

Le milieu environnant aquatique tel que lacs, fleuves et mers ne peut pratiquement plus assurer, dans des conditions de rapidité satisfaisante, l'épuration chimique et microbienne des eaux usées, toujours plus usées de par l'accroissement des populations, de l'industrialisation et du haut degré de développement. L'épuration chimique ne peut alors se faire valablement que dans les milieux particuliers tels que les stations de traitement où sont réunis, le plus souvent en grand volume, les eaux usées d'une localité. Dans ce milieu vont cohabiter les «bonnes et les mauvaises bactéries». Si dans de tels milieux, et principalement par des moyens artificiels mimants souvent la nature, il est possible de valoriser le rendement de la métabolisation des molécules organiques des milieux aqueux par des micro-organismes de plus en plus spécialisés dont la connaissance encore imparfaite implique de nombreuses recherches, à l'inverse il est à craindre, et les preuves ne manquent pas, que ce "rassemblement " des eaux usées soit à l'origine d'une concentration de bactéries et micro-organismes pathogènes.

Si l'unanimité est faite sur l'utilité du traitement des eaux usées en vue de l'obtention d'une eau chimiquement acceptable sur le plan de l'environnement, il n'en est pas de même pour les traitements visant à abaisser, dans des proportions qu'il reste encore à définir, le taux des organismes pathogènes dans les rejets des stations de traitement. Sans vouloir ouvrir le débat il reste à confirmer ou à infirmer que les bactéries té- 


\section{ÉDITORIAL}

moins de contamination fécale sont effectivement de vrais témoins pour apprécier l'action de disparition des bactéries pathogènes et à plus forte raison des virus même entériques. La recherche directe des bactéries et virus pathogènes dans les eaux usées et superficielles doit être, malgré les difficultés techniques considérables, un axe de recherche pour les microbiologistes.

L'étude de la structure des populations des micro-organismes des écosystèmes que sont, milieux néoformés, les boues activées, les lits bactériens et les lagunes de stabilisation des ouvrages de traitement peut et doit permettre l'amélioration du rendement de ces stations biologiques. Cette étude des populations microbiennes ne peut être abordée valablement que grâce à l'optimisation d'un protocole d'échantillonnage visant à contrôler leur hétérogénéité temporelle et spatiale et permettant entre autre d'appréhender la notion de fux microbien et son évolution à travers un ouvrage d'épuration déterminé. Ainsi par la multiplicité des échantillons dans l'espace et dans le temps et par l'uniformisation et la standardisation des techniques d'étude, le volume et la qualité des résultats obtenus permettent avec un maximum de sécurité le traitement statistique des données. De plus si de telles études incluent une approche qualitative des populations de micro-organismes, elles autorisent une application des techniques automatiques d'analyse des données ouvrant la voie par exemple à la classification puis l'identification des bactéries hétérotrophes aérobies présentes dans les eaux usées.

A côté de ce grand groupe bactérien, responsable de la dégradation non spécialisée de la matière organique dans le sens large du terme, existent d'autres groupes de microorganismes tels que les bactéries autotrophes aérobies, les bactéries photosynthétiques et le phytoplancton et même certaines bactéries anaérobies, groupes qui participent aux grands cycles de la matière (azote, carbone, soufre et à l'extrême méthane). La biomasse non négligeable résultant du développement de ces micro-organismes peut être envisagée comme source d'énergie exploitable.

La mise au point de nouvelles méthodes d'étude, telles que milieux de culture très sélectifs permettant l'isolement, l'étude taxonomique et le suivi de l'évolution de ces populations est certainement, à notre avis, un axe de recherches fondamentales qui peut déboucher rapidement sur des applications dont la place dans le cadre des énergies nouvelles ne doit échapper à personne.

Si la microbiologie des eaux usées, terme pris dans le sens de l'hygiéniste, peut apparaître, à l'aube $d u X X \mathrm{I}^{\mathrm{e}}$ siècle, comme une science de peu d'utilité au sein de nos sociétés modernes qui affichent un confort hygiénique trop évident, la vigilance cependant doit être de mise pour tous les organismes et laboratoires dont le rôle est le maintien de la santé publique.

De l'étude de l'évolution des populations des micro-organismes des eaux usées l'ingénieur en traitementépuration peut et doit attendre une nette amélioration de la dégradation biologique des molécules organiques synthétiques.

Enfin la mise en valeur des produits de déchets des micro-organismes des eaux usées et de leurs biomasses, si utopique il y a encore une décennie, entre tout à fait aujourd'hui dans le cadre de la récupération et de l'utilisation des déchets à des fins énergétiques.

Bernard BALEUX 